\title{
AC 2008-1752: UNDERGRADUATE RESEARCH IN NEW CONCEPTS IN SOLAR ENERGY CAPTURE: THEORY, MODELING AND SIMULATION
}

\section{Samuel Lakeou, University of the District of Columbia}

Esther Ososanya, University of the District of Columbia

Wagdy Mahmoud, University of the District of Columbia

Fatou Mbengue, University of the District of Columbia

Fatou Mbengue is a junior in the program of Electrical Engineering

Bodjona Coboyo, University of the District of Columbia

Bodjona Coboyo is a junior in the program of Electrical Engineering

Abdulaziz SIrag, University of the District of Columbia

Abdulaziz Sirag is a graduating senior in the program of Electrical Engineering

Ben Latigo, University of the District of Columbia 


\section{Undergraduate Research in New Concept in Solar Energy Capture: Theory, Modeling, and Simulation}

\section{Introduction}

This work describes a newly initiated undergraduate research work on new concept in solar energy capture. Recently reported photovoltaic efficiencies of novel solar terrestrial concentrator cells have reached record levels. In fact, it is reported that metamorphic, or lattice-mismatched, GaInP/ GaInAs/ Ge 3-junction cells have reached 40.7\% efficiency . Efficiency higher that $40 \%$ was also reported from measurements on lattice-matched 3junction cells. Under such dramatic changes, research on all aspects of solar cells, including theory, modeling and simulation should be highly encouraged at the earliest level in engineering curricula. Solar energy is a major source of alternative energy and is poised to reach more than $160 \mathrm{GW}$ in the US by 2025 . The scarcity of courses dedicated solely to renewable energy and particularly to solar energy in most undergraduate curricula will weigh negatively on the preparation of undergraduate engineering and science students to tackle the expected renewable energy boom in the $21^{\text {st }}$ century. The undergraduate research project started in the department of electrical engineering at UDC is intended to fill this gap. A thorough understanding of the solar cell theory as well as a good understanding of the ongoing worldwide research on solar cells will lay a good ground for meaningful undergraduate research on the subject.

Keywords: III-V Semiconductors, Concentrator Cells, High-Efficiency, Multijunction Solar Cell, Gallium Arsenide Based Cells, Lattice-Mismatched, Metamorphic

\section{Solar Energy Basics}

\section{a. Solar cell equations}

The basic structure of a solar cell is an illuminated (collection of photons, hv) P-N junction as depicted in Fig. 1. When the junction is not illuminated, there exists a junction built-in potential resulting from the formation of a space charge zone at the junction level as shown in Fig. 2. When the junction is uniformly illuminated by photons with hv $>$ Eg (energy gap of the junction material), electron-hole pairs (EHP) will be generated at a rate $\mathrm{g}_{\mathrm{op}}\left(\mathrm{in} \mathrm{EHP} / \mathrm{cm}^{3} . \mathrm{s}\right.$ ) and will participate in the diode current. Neglecting the recombination and generation within the space charge zone $\mathrm{W}$, the photogenerated current, directed from $\mathrm{N}$ to $\mathrm{P}$ will subtract from the total current in the diode from $\mathrm{P}$ to $\mathrm{N}$. The total electrons generated per second within the $\mathrm{N}$ and $\mathrm{P}$ regions (with cross sectional area $\mathrm{A}$ ) is $\left(\mathrm{A} L_{n} \mathrm{~g}_{\mathrm{op}}+\mathrm{A} L_{p} \mathrm{~g}_{\mathrm{op}}\right)$, where $\mathrm{L}_{\mathrm{n}}$ and $\mathrm{L}_{\mathrm{p}}$ represent the diffusion length of the holes in the $\mathrm{N}$ region and of the electrons in the $\mathrm{P}$ region respectively. 
The final I-V relationship of an illuminated diode is therefore:

$$
I=q A\left(\frac{L_{p}}{\tau_{p}} p_{n}+\frac{L_{n}}{\tau_{n}} n_{p}\right)\left(e^{q V / k T}-1\right)-q A g_{o p}\left(L_{p}+L_{n}\right)
$$

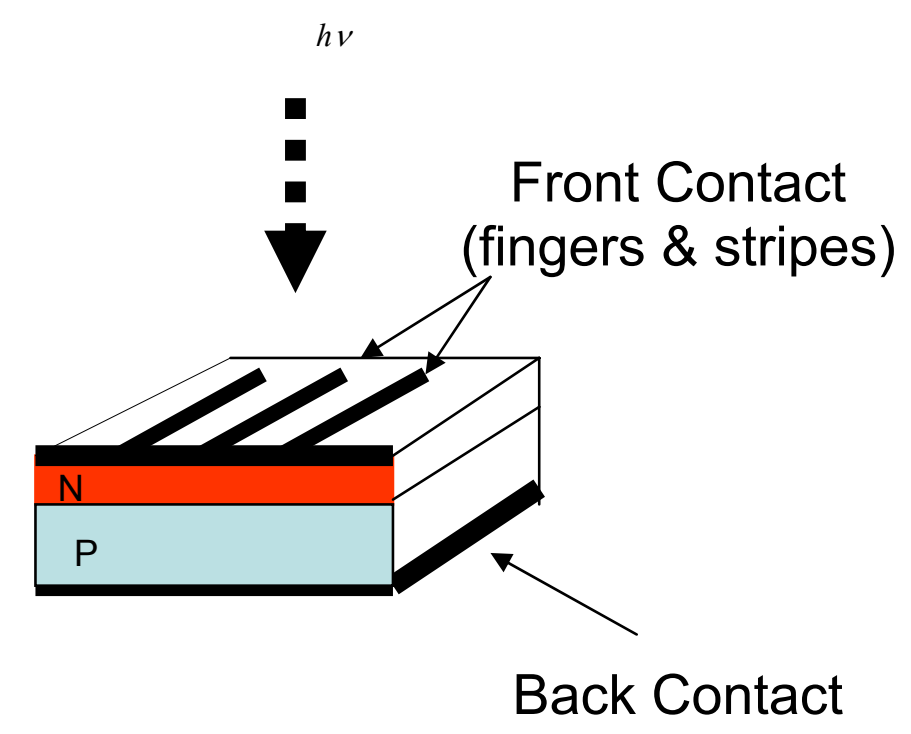

Fig. 1 Generic solar cell structure

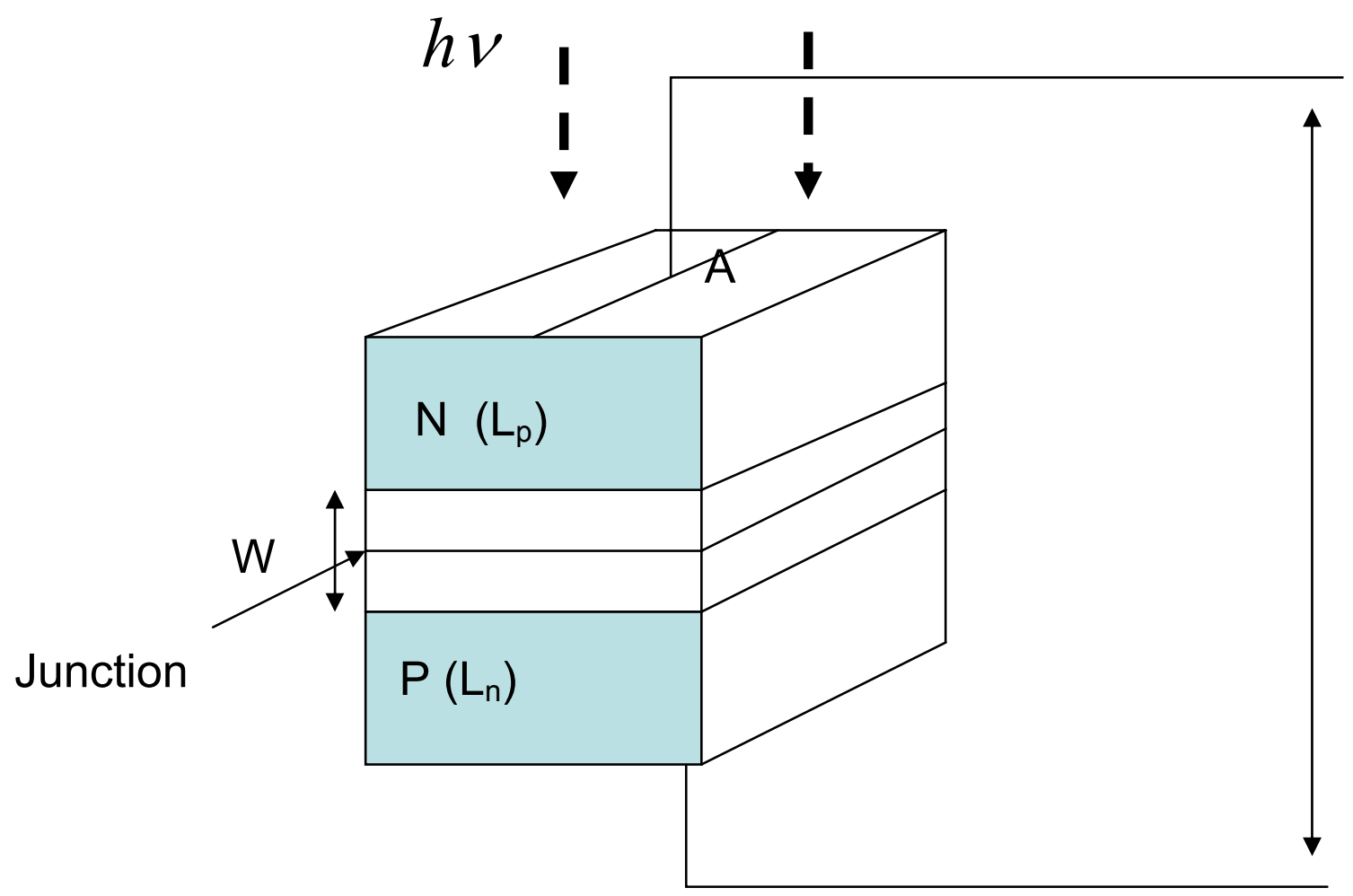

Fig. 2 Illuminated P-N Junction diode (not to scale) 
Under a short circuit condition ( $\mathrm{V}=0$ ), the diode current of equation (1) will be reduced to the short circuit current $\mathrm{I}_{\mathrm{sc}}=\mathrm{I}_{\mathrm{op}}$ given by:

$$
\mathrm{I}_{\mathrm{sc}}=\mathrm{I}_{\mathrm{op}}=\left(\mathrm{A} L_{n} \mathrm{~g}_{\mathrm{op}}+\mathrm{A} L_{p} \mathrm{~g}_{\mathrm{op}}\right)
$$

When the diode is not loaded or when there is an open circuit across the diode, the total current $\mathrm{I}=0$. The corresponding voltage $\mathrm{V}=\mathrm{V}_{\mathrm{oc}}$ is the open circuit voltage and is expressed by:

$$
V_{o c}=\frac{k T}{q} \ln \left[\frac{L_{n}+L_{p}}{\left(L_{p} / \tau_{p}\right) p_{n}+\left(L_{n} / \tau_{n}\right) n_{p}} \cdot g_{o p}+1\right]
$$

An illuminated diode can therefore generate power but not much power can be delivered by a single junction which will have a voltage less than its contact potential $(<1 \mathrm{~V}$ for $\mathrm{Si})$. However, the short circuit current generated by an area of $1 \mathrm{~cm} 2$ can vary from 10 to $100 \mathrm{~mA}$ ! If several cells are combined in parallel, the resulting current can be considerably higher. If they are combined in series the open circuit voltage can also be increased considerably.

The maximum power that a cell can deliver to a load is obtained when $V I=V_{m} I_{m}$.

The fill factor (FF) is defined by the ratio $\frac{V_{m} I_{m}}{I_{s c} V_{o c}}$ and represents a figure of merit of the cell.

The optical energy resulting from illumination is best utilized if the cell is designed with a large area junction located near the surface of the device. The junction depth must be less than the diffusion length $\mathrm{Lp}$ of holes in the $\mathrm{N}$ material to allow holes generated near the surface to diffuse to the junction before they recombine. Similarly, the thickness of the $\mathrm{P}$ region must be such that the electrons generated in the $\mathrm{P}$ region can diffuse to the junction before they recombine.

\section{b. Review of some photovoltaic production options}

There are mainly two technology options for solar production: flat plate or concentrators. Flat plate technology includes crystalline silicon and thin films of various semiconductor materials as well as organic polymers and nanomaterials. The concentrator technology uses a system of lenses or reflectors to magnify and focus the incident solar illuminations

for higher efficiencies ${ }^{1,2,3}$. Table 1 provides a breakdown of the PV module production in 2003: 


\begin{tabular}{|l|c|c|}
\hline \multicolumn{1}{|c|}{ Technology } & $\begin{array}{c}\text { Worldwide production } \\
\text { in MW }\end{array}$ & $\begin{array}{c}\text { Percentage } \\
\text { \%o }\end{array}$ \\
\hline Flat plate, single -crystal Si & 230.5 & 31 \\
Poly crystalline Si & 443.8 & 59.6 \\
Ribbon Si & 22.8 & 3.1 \\
Thin film amorphous Si & 39.3 & 5.6 \\
Thin film Cadm. Tellurire & 3 & 0.4 \\
Thin film CiGs & 4 & 0.5 \\
\hline Concentrators Si & 0.7 & 0.1 \\
\hline
\end{tabular}

Table1. World wide PV production by technology type (Source: NREL ${ }^{4}, 2003$ )

\section{c. Typical electrical model of a junction solar cell}

A typical model resulting from the equation (1) is shown in Fig. 3.
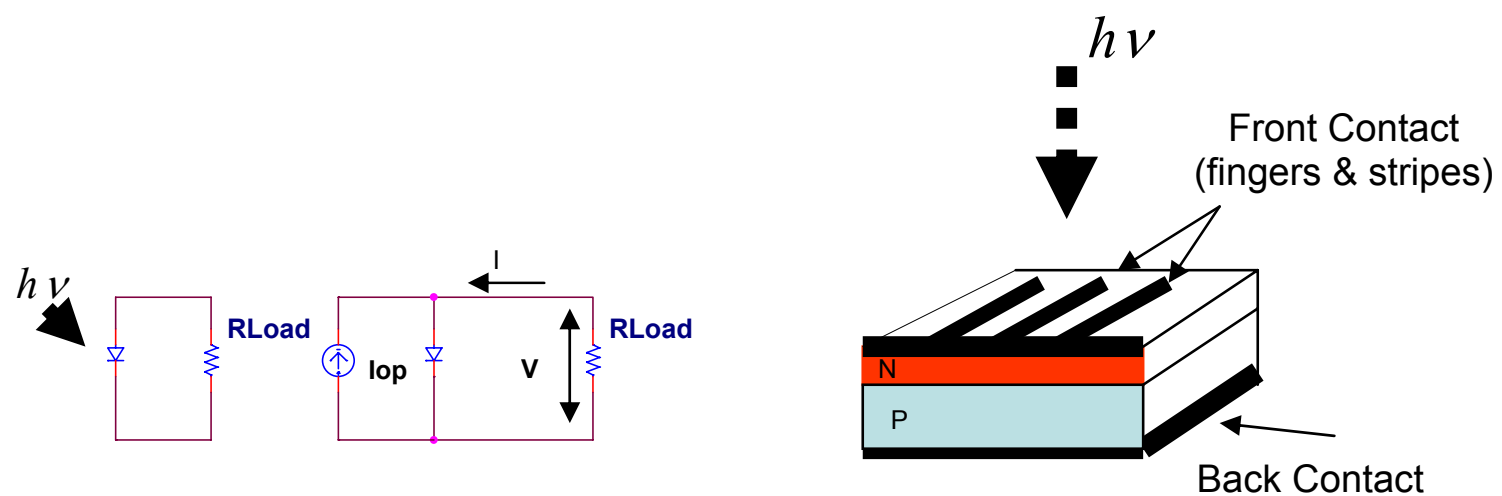

Fig. 3 Model of a solar cell junction under illumination

\section{d. Ideal conversion efficiency}

The conversion efficiency $\eta$ is defined by ratio of the maximum power output $P_{m}$ to the incident power $\mathrm{P}_{\mathrm{in}}, \boldsymbol{\eta}=\mathbf{P}_{\mathbf{m}} / \mathbf{P}_{\text {in }}$. It is found to be $31 \%$ for $\mathrm{E}_{\mathrm{g}}=1.35 \mathrm{eV}^{\mathbf{5}}$, using material parameters characteristics of III-V semiconductors at $300 \mathrm{~K}$ and under one sun AM1.5 (air mass 1.5 condition represents a satisfactory energy weighted average for terrestrial applications equivalent to $844 \mathrm{~W} / \mathrm{m} 2$ incidence power). This number can reach $37 \%$ under an optical concentration of 1000 suns (i.e $844 \mathrm{KW} / \mathrm{m} 2$ incidence power) AM1.5. A well made Si cell can reach a little over $10 \%$ efficiency providing approximately $100 \mathrm{~W} / \mathrm{m} 2$ of electrical energy under full illumination.

Also, for a multiple-band scheme under solar concentration, the maximum efficiency can be increased significantly. For two band gaps in series, the ideal maximum efficiency is $50 \%$ with $\mathrm{E}_{\mathrm{g} 1}=1.56 \mathrm{eV}$ and $\mathrm{E}_{\mathrm{g} 2}=0.94 \mathrm{eV}$. For three bandgaps, the ideal maximum 
efficiency is $56 \%$ with $\mathrm{E}_{\mathrm{g} 1}=1.56 \mathrm{eV}, \mathrm{E}_{\mathrm{g} 2}=1.18 \mathrm{eV}$ and $\mathrm{E}_{\mathrm{g} 3}=0.75 \mathrm{eV}$. However, for more than three bandgaps the efficiency increases very slowly; at 36 bandgaps, the maximum efficiency is $72 \%$.

\section{Recent advanced multigap cell structures}

\section{a. Basic structure}

Among the most recent multiple bandgap structures' the structure depicted in Fig. 4 is typical.

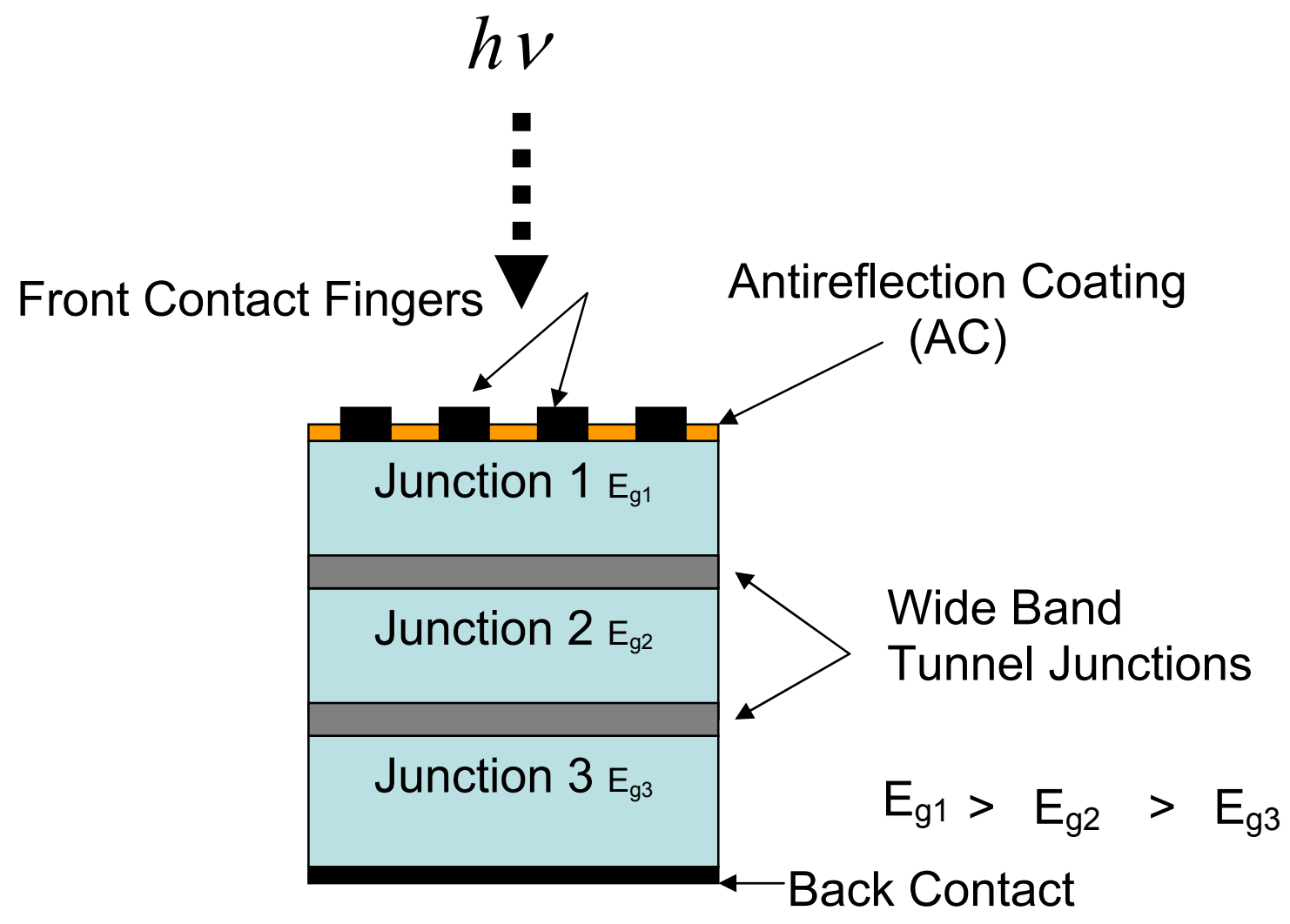

Fig 4. Multijunction solar cell structure

(A typical structure includes $\mathrm{GaInP}_{2} / \mathrm{GaAs} / \mathrm{Ge}$ junctions)

The junctions are stacked one on top of the other with interfaces made with tunnel diodes. It is to be noted that an incident light which does not contain all the wavelengths required to "turn on" their corresponding junction will not activate the multijunction cell.

\section{b. Possible model}




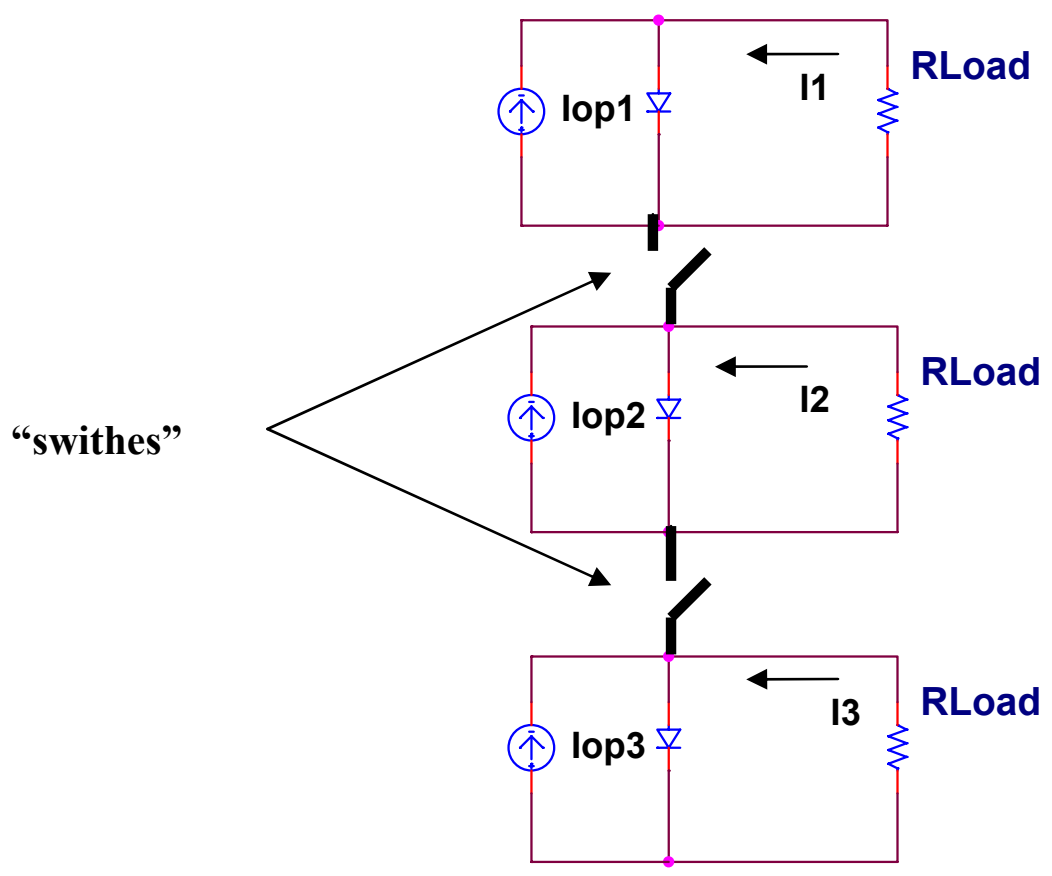

Fig. 5 Triple Junction solar cell's electrical model

In this model, the "switches" inserted between the junctions will not be connected unless the incident illumination contains the required wavelengths capable of activating all the junctions.

\section{Experimental setup for spectral response}

The initial proposed experimental setup in Fig. 6 will include a light source and a concentrator to produce up to 800 suns, a chopper and a computer controlled characterization apparatus.

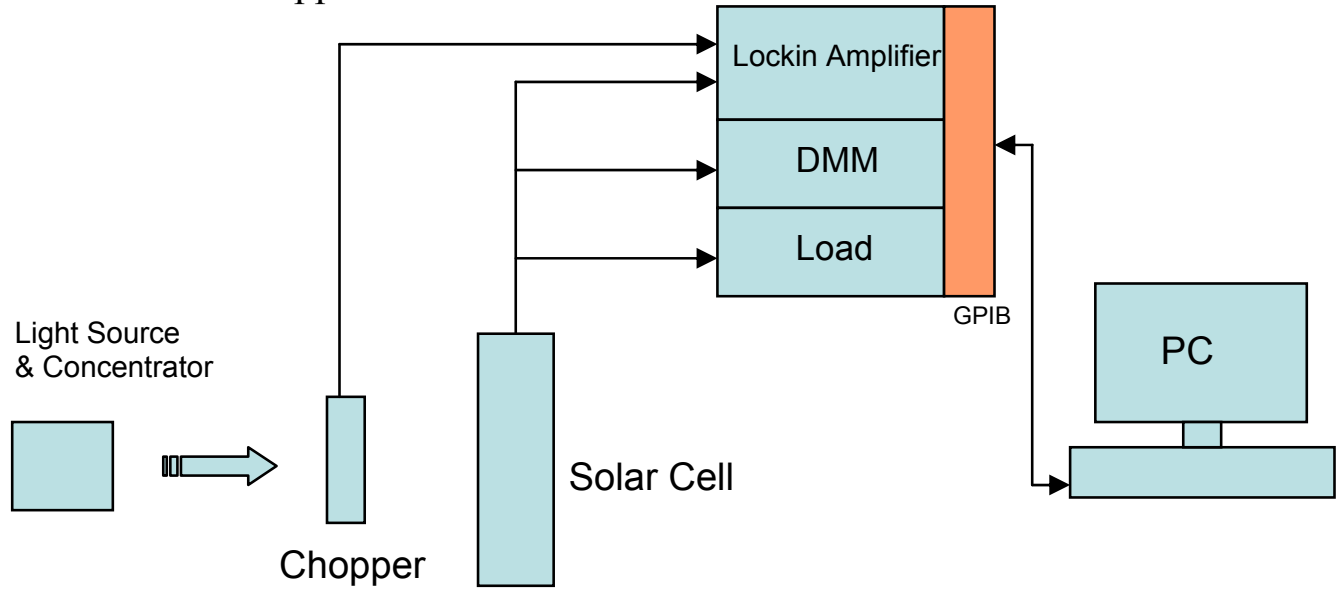

Fig. 6 Proposed solar cell test setup 
At an initial stage, the objective of this research is to explore, study single low cost crystals manufactured through material engineering, containing multiple junctions that are capable of capturing 60 to 70 percent of the sun's energy.

Triple junction solar cell samples from Spectrolab ${ }^{6}$ as shown in Fig. 7 will first be considered for evaluation.

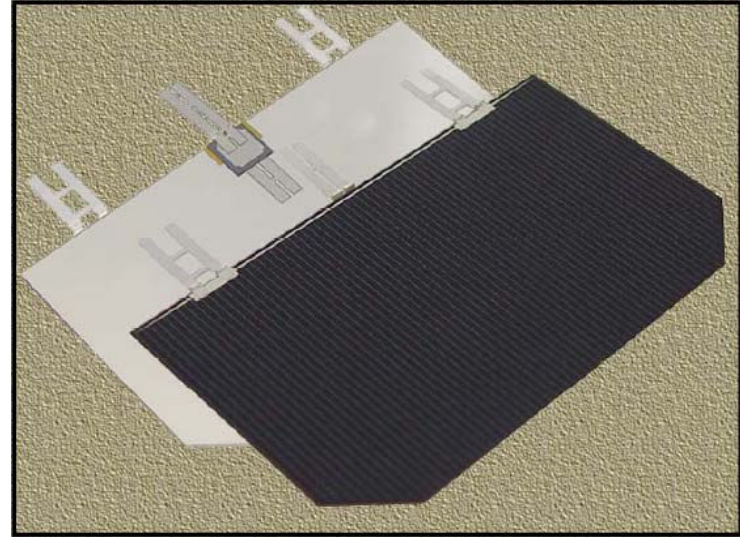

\begin{tabular}{|c|c|}
\hline \multicolumn{2}{|c|}{ Product Description } \\
\hline Substrate & Germanium \\
\hline Solar Cell Structure & $\mathrm{Galn} \mathrm{P}_{2} / \mathrm{GaAs} / \mathrm{Ge}$ \\
\hline $\begin{array}{l}\text { Method of GaAs } \\
\text { Growth }\end{array}$ & Metal Organic Vapor Phase Epitaxy \\
\hline Device Design & $\begin{array}{l}\text { Monolithic, two terminal triple junction. } \\
n / p \text { Galn } P_{2}, G a A s \text {, and } G e \text { solar cells } \\
\text { interconnected with two tunnel } \\
\text { junctions }\end{array}$ \\
\hline Sizes & Up To $32 \mathrm{~cm}^{2}$ \\
\hline Assembly Method & $\begin{array}{l}\text { Multiple techniques including } \\
\text { soldering, welding, } \\
\text { thermocompression, or } \\
\text { ultrasonic wire bonding }\end{array}$ \\
\hline
\end{tabular}

Fig. 7 A triple junction solar cell from Spectrolab (Photograph courtesy Spectrolab Inc.)

The study of these materials requires a thorough understanding of the physics governing the solar capture process in each case and modeling and simulation for better prediction of their performance and device modeling.

We will analyze the behavior of the device over a wide range of wavelengths and fit the calculated data and experimental observations.

\section{Modeling and simulation}

Modeling and simulation will be conducted using commercially available modeling and simulation tools. It is anticipated that low cost licensing will be available for conducting such a study. An initial communication with SILVACO $^{7}$ has resulted in a very low price quote for the acquisition of a 20-seat license of the Lumminus 2D/3D simulation package from the ATLAS framework which is well suited for solar cell simulation. Samples for evaluation will be sought from all available advanced solar cell manufacturers and universities with manufacturing capabilities.

The following device modeling will be conducted on the new multi junction material structures, and simulated using the ATLAS simulation software package from SILVACO:

i) Two and three dimensions (2D / 3D) modeling and simulation of the electrical, optical and thermal behaviors of multi junction and compound semiconductor (silicide) devices; 
ii) Thin film transistors used in the construction of solar cells;

iii) Modeling of light absorption and photo-generation in non-planar multi junction semiconductor solar cell devices;

iv) Non-isothermal modeling and simulator of the local thermal effects on physical constants of devices, and quantum confinement effects on carrier transport in multi junction devices;

v) Modeling and analysis of non-planer structures for internal and external reflections and refractions; and

vi ) Polarization dependencies and dispersion, and the computation of key device characteristics such as quantum efficiency, and spectral and frequency responses.

The ATLAS software package is an integrated, computer-aided development environment for high performance, nano-scale semiconductor devices and custom IC designs. The software package is also composed of a large number of technology development and custom IC design tools.

\section{Student participation}

The research work is currently undertaken by three faculty and three undergraduate students in the program of electrical engineering at UDC. The students are guided by the faculty in their literature search and are expected to report regularly on their findings. It is expected that a larger number of students will be participating in the project as the initial experimental setup is completed and tested.

\section{Conclusion}

Participation of undergraduate students in research on renewable energy topics, particularly on solar energy related topics is at the order of the day. Solar energy production is poised to reach $160 \mathrm{GW}^{\mathbf{8}}$ in the US by 2025 . Academic institutions are expected to take the lead in disseminating renewable energy topics in their student bodies as well as in the community at large. We are confident that this research work will make its modest contribution to achieving this goal. The work is currently supported by a grant from the National Science Foundation (SBIR, ECCS-0749319).

\section{References:}

[1] FABRICATION OF HIGH EFFICIENCY MICROCRYSTALLINE AND MICROMORPH THIN FILM SOLAR CELLS ON LPCVD ZnO COATED GLASS SUBSTRATES C. Ballif, J. Bailat, D. Dominé, J. Steinhauser, S. Faÿ, M. Python, L. Feitknecht 
[2]. Most efficient solar cells made possible by new material, K. Yu et. al. Physical Review Letters, 2003 [3] MULTIJUNCTION SOLAR CELLS WITH OVER 40\% EFFICIENCY AND

FUTURE DIRECTIONS IN CONCENTRATOR PV Richard R. King, Daniel C. Law, Ken M.

Edmondson, Chris M. Fetzer, Geoff S. Kinsey, Hojun Yoon, Raed A. Sherif, Dimitri D. Krut, James H.

Ermer, Peter Hebert, Peichen Pien, and Nasser H. Karam Spectrolab, Inc., $22^{\text {nd }}$ EUPVSEC, Milan Italy

International (http://www.silvaco.com).

[4] National Renewable Energy Laboratory, http://www.nrel.gov

[5] Limiting efficiency of Ideal Single and Multiple Energy Gap Terrestrial Solar Cells, J. Applied Physics, $51,4494(1980)$

[6] Spectrolab, INC. http//www.spectrolab.com

[7] SILVACO's ATLAS User's Manual. Device simulation Software. Volumes I and II. Silvaco

[8] The outlook on Renewable Energy in America Vol II: Joint Summary, ACORE March, 2007 